DOI: $10.31249 / \mathrm{rsm} / 2018.03 .07$

\title{
Л.Б. Вардомский
}

\section{СОСТОЯНИЕ И ПЕРСПЕКТИВЫ ВЗАИМНЫХ ЭКОНОМИЧЕСКИХ ОТНОШЕНИЙ БЕААРУСИ, РОССИИ И УКРАИНЫ В КОНТЕКСТЕ ИХ ИАЕНТИЧНОСТИ}

Аннотация. В статье анализируется динамика взаимных экономических связей Беларуси, России и Украины в 2010-2017 г2. в контексте формирования их государственной идентичности. Расхождение в самоидентификации стран сказалось на их интеграционных приоритетах и характере взаимных связей. Особенно сильно это проявилось в российско-украинских отнотениях, поскольку проевропейская идентичность Украины формировалась на национальной основе и противопоставлении себя России. Политический разрыв России и Украины приобрел долгосрочный характер. В этих условиях иентральное место в восточнославянском треугольнике заняла Беларусь, которая в соответствии со своей идентичностью готова стать зоной «сборки» запада и востока Европьл.

Ключевые слова: Беларусь, Россия, Украина, идентичность, торговые связи.

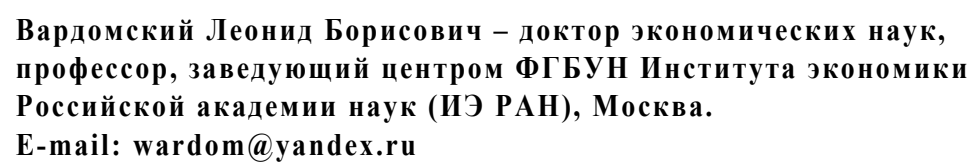

L.B. Vardomsky. The State and Prospects of Mutual Economic Relations Between Belarus, Russia and Ukraine in the Context of Their Identity

Abstract. The dynamics of mutual economic ties between Belarus, Russia and Ukraine in 2010-2017 is analyzed in the context of the formation of state identity. The discrepancy in the countries' self-identification affected their integration priorities and the nature of their mutual ties. This was especially evident in Russian-Ukrainian relations, since the pro-European identity of Ukraine was formed on a national basis and opposed to Russia. The political gap between Russia and Ukraine has acquired a long-term character. In this situation, the central place in relations in the East Slavic triangle was occupied by Belarus, which, in accordance with its identity, is ready to become the "assembly" zone of the West and East of Europe.

Keywords: Belarus, Russia, Ukraine, identity, trade relations. 


\title{
РОССИЯ И МИР В ХХІ ВЕКЕ
}

\author{
Vardomsky Leonid Borisovich - Doctor of Economics, Professor, \\ Head of the Center, FGBUN Institute of Economics, \\ Russian Academy of Sciences. Moscow. E-mail: wardom@yandex.ru
}

\section{Особенности ГосУАарственной иАентичности} Беларуси, России и Украины

Исследованию идентичности государства посвящена обширная литература, в которой выделяются труды А. Вендта, Р. Арона, И. Призела, А. Тофлера, С. Уолта, С. Хантингтона [3, с. 20-24]. В нашей работе понятие «государственная идентичность» используется в двух взаимосвязанных смыслах: как приверженность населения ценностям страны и как набор характеристик, через которые страна отождествляется с некими миссиями для внешнего окружения - «бренд государства». В целом же государственная идентичность отражает осознанные возможности развития и степень их реализации. Это институт, оказывающий сильное влияние на масштабы и структуру внешнеэкономических связей.

Одним из первых среди российских ученых на связь идентичности и интеграции России в мировую экономику обратил внимание Д.В. Тренин [9]. Теме взаимосвязи национальной и коллективной идентичности посвящены также исследования А.М. Бусыгиной, В.В. Кочеткова, В.Е. Морозова, Н.Л. Прохоренко, Г.Г. Салихова, И.С. Семененко, В.С. Степина.

Во время формирования идентичности государств происходит выбор социокультурных и внешнеполитических приоритетов, которые в наибольшей степени соответствуют задачам национальной модернизации. В случае постсоветских стран речь идет о выборе между присоединением к европейской интеграции, созданием своего евразийского объединения или проведением многовекторной внешней политики. В этом контексте весьма интересно развитие сотрудничества стран восточнославянского треугольника, становление идентичности которых определяет систему их внутренних и внешних интересов. Через призму этих интересов выстраиваются взаимные отношения и создаются инструменты как их стимулирования, так и реагирования на возникающие политические и экономические разногласия.

На постсоветском пространстве Беларусь, Украина и Россия - наиболее развитые государства, экономики которых были исторически тесно взаимосвязаны. Кроме того, они весьма близки в культурно-цивилизационном плане. После обретения независимости перед ними встали задачи формирования новой государственной идентичности и модернизации национальной экономики. Они их решали и решают по-разному исходя из исторического опыта, имеющихся ресурсов, с учетом тенденций современного развития и происходящих политических и экономических изменений во внешнем окружении, в том числе у рассматриваемых стран-соседей. 
Страны славянского треугольника были инициаторами распада СССР, правда руководствуясь разными целями. Украинское и белорусское руководство стремилось к реальной независимости своей страны, а российское, в лице Б. Ельцина, стремилось через суверенитет России прийти к власти, быстро провести рыночные реформы, войти в сообщество развитых демократий и возвратить лидерство на постсоветском пространстве.

Стремление Украины к независимости от России объясняется рядом причин. Одна из них - неверие украинских элит в Россию как государство, ожидание длительного внутрироссийского конфликта и неминуемого распада страны, что было связано с обострением в 1990-е годы межэтнических отношений, внутриэлитных конфликтов и «парадом» региональных суверенитетов.

Вторая причина связана с тем, что распад СССР активизировал формирование украинского национального самосознания, опиравшегося на память о гетманщине и событиях, связанных с ее возникновением, существованием и ликвидацией [4, с. 143]. Учитывая же западноукраинский (галицкий) фактор, руководство новой Украины с самого начала делало упор на формирование украинской идентичности как части европейской цивилизации, а не как части «Русского мира» ${ }^{1}$. Однако галицкое понимание идентичности не разделяло население Восточной Украины. Этот внутриукраинский раскол порождал политическую слабость государства, которую усугубляло формирование во второй половине 1990-х годов так называемой двойной институциональной системы, при которой возникали новые социальные институты, но при этом в полном объеме действовали институты, унаследованные от советского времени [2, с. 312-316]. Такая система создавала благоприятные условия для коррупции и сращивания политики и бизнеса, что усугубляло неэффективность управления.

Третья причина обусловлена неприятием украинской элитой политической системы России с ее высокой централизацией власти, что напоминало о царском и советском периодах Украины. В то же время под влиянием экономических успехов Запада она верила в то, что подлинная модернизация страны возможна только на либерально-демократической основе. Националистическими силами Россия рассматривалась политическим противником Украины, не приемлющим ее сближения с Европой, представлялась как реальная угроза ее территориальной целостности и формированию украинской идентичности. Идентичность страны строилась через противопоставление

1. В трактовке понятия «Русский мир» существуют два подхода. Один подход отражает исторически сложивщуюся этнокультурную и лингвистическую близость трех восточнославянских народов, другой - исходит из того, что «Русский мир»это политический лозунг, отражающий постимперские настроения части российской элитьл. 
России. Под влиянием широкого информационного внедрения этих взглядов в украинском обществе формировались проевропейские настроения, которые вылились в подписание Соглашения об ассоциации с ЕС, которое начало действовать с 1 ноября 2014 г. Политический переворот в феврале 2014 г. и захват власти представителями радикально-националистических партий круто изменил внутреннюю и внешнюю политику государства, Украина потеряла Крым и погрузилась в гражданскую войну.

Для России же Украина выступала как важная часть «Русского мира». Киев для России является сакральным символом единой Русской земли [8]. Россия была заинтересована в широкой экономической интеграции с Украиной и возвращении через это статуса великой державы. Государственная идентичность России в силу ее многонациональности не может опираться на этническую основу.

К концу 1990-х годов у руководства России возникло понимание того, что в «евроатлантическом клубе избранных» ее трактуют как сторону, проигравшую в «холодной» войне, а не как равного партнера. Идентичность на основе либеральной рыночной экономики и евроатлантических ценностей превращает страну в объект международной политики, порождает громадное социальное неравенство и создает большие риски ее дальнейшего существования.

При Президенте В. Путине начинает формироваться новая идентичность России как одного из центров полицентричного мироустройства, как равного ведущим странам Запада «центра силы», как государства «суверенной демократии». В этом контексте постсоветское пространство рассматривается Россией как зона ее особых интересов, поскольку консолидация евразийского пространства неразрывно связана с укреплением статуса России как великой державы. Нынешняя идентичность страны формируется в рамках системы глобального капитализма, но на основе сохранения суверенитета и права следовать традиционным для постсоветской Евразии ценностям [5, с. 146-148]. Такая политика РФ вызывает резкое неприятие Запада, усматривающего в этом ее «имперские амбиции». По сути дела, речь идет о борьбе Запада и России за постсоветское пространство, в которой сталкиваются исторические интересы России и Запада, стремящегося геополитически и экономически закрепить свою победу в холодной войне.

Идентичность Республики Беларусь строится не на этнической, а на гражданской основе. В Беларуси, в отличие от Украины, не укоренился восточноевропейский этнонационализм, а идеологическими основаниями современного белорусского государства стали индустриальная идентичность, государственная символика, культ победы в Великой Отечественной войне. Главной целью государства стало сохранение унаследованной от СССР экономики. Этим объясняется ее отставание по ходу рыночной трансформации 
от России и Украины. Вместе с тем Беларусь, укрепляя свой суверенитет, считает себя частью Русского мира в его этнокультурном понимании и ориентируется на традиционные для русской цивилизации ценности. Белорусское государство привержено евразийской интеграции, рассматривает себя как «точку сборки» Евразии, центр традиционной Европы, но при этом стремится стать коммуникационным мостом между западом и востоком Европы $[1]$.

\section{Аинамика внешней и взаимной торговяи}

Период 2010-2017 гг. был богат на принципиальные изменения в мировой и региональной политике и экономике. В это время произошло обострение противоречий между США и их союзниками, пытающимися сохранить и укрепить свои преимущества в мировом хозяйстве, с одной стороны, и странами, стремящимся к равенству с ними в рамках концепции полицентричного мироустройства, - с другой. Стремление к равенству обусловлено ростом доли ряда крупных развивающихся стран (например, КНР, Индии, Турции, Бразилии) в мировой экономике при сокращении доли стран Запада. Важным фактором обострения противоречий стали усиление социального неравенства между странами мира и внутри стран, непропорциональный рост финансового сектора мировой экономики, в котором ведущую роль играют страны Запада. Нестабильность мировой экономики тесно связана с динамикой мировых цен на углеводороды, колебаниями трансграничного движения капиталов, ростом совокупной задолженности и рисков инвестиционной деятельности. В эти противоречия широко вовлечены страны «славянского треугольника».

Несмотря на различия в моделях и размерах, национальные экономики рассматриваемых стран практически одинаково реагировали на колебания мировой конъюнктуры: на Украине до 2012 г., Беларуси и РФ до 2013 г. происходил восстановительный рост экономики, который сменился замедлением роста, а затем и спадом, который длился около двух с половиной лет. Пик кризиса у всех рассматриваемых стран пришелся на 2015 г. В 2016 г. по отношению к 2013 г. ВВП Украины сократился на 13,2\%, у Беларуси - на 6,3 и у РФ - на 3\% (данные Статкомитета СНГ, постоянные цены). На Украине спад начался раньше, но и закончился раньше: в 2016 г. ВВП страны увеличился на $2,3 \%$. У РБ и РФ рост экономики возобновился в 2017 г. Следует отметить, что страны славянского треугольника в рассматриваемый период развивались медленнее, чем постсоветское пространство (без стран Балтии) в целом. В результате этого их суммарная доля в общем ВВП стран СНГ и Грузии за 2010-2016 гг. сократилась с 85,1 до 81,5\%, в том числе РФ - 
с 75,6 до 73,5\%, Украины - с 6,7 до 5,3\%, Беларуси - с 2,8 до 2,7\% (рассчитано по данным Мирового банка).

Спад и общее замедление развития объясняется разными причинами: исчерпанием подъемной силы модели сырьевого развития, попаданием РФ в «ловушку среднего дохода», неразвитостью рыночных институтов и финансовых систем. В любом случае сложившаяся в странах после обретения независимости структура экономики оказалась сильно подвержена возросшей турбулентности мирового хозяйства.

Однотипную реакцию экономики стран на низкую мировую конъюнктуру хорошо иллюстрирует динамика внешнего товарооборота. У РБ внешний товарооборот в 2016 г. составил $55,2 \%$ от уровня 2012 г., взятого за $100,0 \%$ (92,5 млрд долл.). У РФ сокращение было примерно таким же: $54,8 \%$ от объема 2012 г. в 863,2 млрд долл. Объем внешней торговли Украины в 2016 г. составил 49\% от уровня 2012 г. (154,5 млрд долл. $)^{2}$.

Падение же взаимной торговли различалось значительно сильнее (табл. 1). Взаимный товарооборот РФ и РБ в 2016 г. составил около $60 \%$ от объема 2012 г., т.е. сократился меньше, чем внешний товарооборот каждой из стран в целом. Это можно объяснить действием общего таможенного пространства, использованием во взаимных расчетах национальной валюты, реализацией такого крупного инвестиционного проекта, как Белорусская АЭС.

\section{АИНАМИКА ВНЕШНЕТОРГОВЫХ СВЯЗЕЙ}

\section{МЕЖАУ РЕСПУБАИКОЙ БЕААРУСЬ, РФ И УКРАИНОЙ}

\begin{tabular}{|l|l|c|c|c|c|c|c|c|}
\hline $\begin{array}{l}\text { Tоваро- } \\
\text { оборот }\end{array}$ & Показатели & 2010 & 2011 & 2012 & 2013 & 2014 & 2015 & 2016 \\
\hline \multirow{2}{*}{ РФ - РБ } & млрд долл. & 28,0 & 39,4 & 43,9 & 39,7 & 37,4 & 27,5 & 26,2 \\
\cline { 2 - 9 } & индекс & 63,8 & 89,7 & 100,0 & 90,4 & 85,2 & 64,6 & 59,7 \\
\hline \multirow{2}{*}{ РФ - РУ } & млрд долл. & 35,6 & 48,9 & 45,0 & 38,3 & 22,5 & 12,3 & 8,7 \\
\cline { 2 - 9 } & индекс & 79,1 & 108,7 & 100,0 & 85,1 & 50,0 & 27,3 & 19,3 \\
\hline \multirow{2}{*}{ РБ - РУ } & млрд долл & 4,5 & 6,1 & 7,3 & 5,6 & 5,6 & 3,2 & 3,7 \\
\cline { 2 - 9 } & индекс & 61,6 & 83,6 & 100,0 & 76,7 & 76,7 & 43,8 & 50,7 \\
\hline
\end{tabular}

Источник: Данные национальной статистики.

Однако интеграционный фактор не смог в полной мере компенсировать потери от ухудшения условий торговли, обусловленные снижением цен на углеводороды и другие экспортные товары с низкой добавленной стоимостью, падением курсов национальных валют, удорожанием внешних заимствований.

2. Рассчитано по данным национальных статистических служб. 
Для сравнения: оборот РФ с Польшей за 2013-2016 гг. сократился более чем наполовину: с 27,9 млрд долл. до 13,1 млрд долл., а оборот Беларуси с Польшей за этот же период уменьшился всего на $15 \%$. Это объясняется устойчивостью спроса польского рынка на белорусские товары, стоимостный объем которого в этот период оставался довольно стабильным. Сокращение оборота было обусловлено в основном уменьшением белорусского импорта из Польши в связи с падением белорусского рубля и общим спадом производства и внутреннего спроса. Резкое снижение российско-польского товарооборота объясняется как падением мировых цен на углеводороды, преобладающие в российском экспорте в Польшу, так и с падением импорта польских товаров РФ в связи с обрушением курса рубля и российскими контрсанкциями.

Взаимная торговля Беларуси и Украины в 2016 г. была чуть выше половины от объема 2012 г., т.е. примерно соответствовала падению внешней торговли этих стран за данный период. Причем максимальное падение взаимной торговли пришлось на 2015 г.

Взаимная торговля РФ и Украины сократилась в 3 раза сильнее, чем общий внешний товарооборот каждой из них. Если динамика взаимной торговли Беларуси и Украины определялась в основном макроэкономическим и структурным факторами и происходила в условиях режима свободной торговли, то падение торговли между Россией и Украиной стало результатом сложения макроэкономических, структурных и политических факторов. В частности, с 1 января 2016 г. Россия приостановила режим ЗСТ для Украины в связи с ассоциацией последней с ЕС и ожидаемым в результате этого ростом европейского реэкспорта в РФ.

Это дает основание предположить, что при отсутствии политических противоречий между странами и взаимных санкций динамика их взаимных связей была бы примерно такой же, как у торговли Беларуси и Украины. Исходя из этого предположения, вклад политики в падение российскоукраинского товарооборота в период 2013-2016 гг. составил примерно 40\%, а $60 \%$ падения объясняется экономическими факторами.

КОЭФФИЦИЕНТ ВНЕШНЕТОРГОВОЙ СВЯЗАННОСТИ

Таблица 2 РБ и РФ, РБ и РУ, РФ и РУ

\begin{tabular}{|l|c|c|c|c|c|c|c|}
\hline Страны & 2010 & 2011 & 2012 & 2013 & 2014 & 2015 & 2016 \\
\hline РБ - РУ & 2,33 & 2,71 & 3,02 & 2,16 & 2,64 & 2,17 & 2,63 \\
\hline РФ - РУ & 2,14 & 2,22 & 1,94 & 1,59 & 1,02 & 0,84 & 0,63 \\
\hline РБ - РФ & 1,77 & 1,89 & 1,96 & 1,72 & 1,75 & 1,93 & 1,97 \\
\hline
\end{tabular}

Источник: Расчеты автора по данным национальной статистики. 
Это предположение подтверждает динамика коэффициента внешнеторговой связанности (КВТС), исчисляемого как отношение стоимостных объемов взаимного товарооборота к суммарному ВВП (в текущих ценах) взаимодействующих стран (табл. 2). Устойчивое сокращение КВТС РФ и Украины, начавшееся в 2012 г., объясняется тем, что внешняя торговля росла медленнее, а падала быстрее, чем сумма ВВП этих стран, выраженная в текущих ценах и по текущему курсу доллара.

Для КВТС РБ и РУ, РБ и РФ в 2010-2016 гг. были характерны колебания без выраженной тенденции. Колебания объясняются, тем, что спад / рост во внешнеторговых связях предвосхищает падение / рост номинального ВВП, на величину которого сильное влияние оказывает курс национальной валюты к доллару.

\section{Через новые технологии \\ к устойчивому развитию \\ белорусско-российских связей}

Белорусско-российские экономические связи довольно значительны в абсолютном и относительном выражении: в 2016 г. на РФ пришлось 51,3\% внешнего товарооборота РБ, а на Беларусь - 5,5\% товарооборота РФ. Для выведения своих товаров на российский рынок Беларусь создала в России разветвленную товаропроводящую сеть в виде магазинов, торговых домов, сборочных производств и соответствующей логистики.

В 2017 г. взаимные торговые связи увеличились на 24\%. Их неустойчивость в 2010-2017 гг. объясняется в основном структурными ограничениями, конъюнктурными колебаниями цен на торгуемые товары и периодически возникавшими между странами «торговыми войнами».

Взаимная специализация стран в большой мере опирается на производства и технологии из советского экономического наследия. Многие традиционные товары взаимной торговли по соотношению цена - качество постепенно уступают товарам из третьих стран или производимым в РФ и РБ, но на основе технологий, заимствованных за рубежом. Торговые войны имели как политическую подоплеку - недостаточную, по мнению российской власти, политическую лояльность белорусского руководства, так и стремление крупных российских компаний вести с РБ дела на более выгодной для себя основе. В свою очередь белорусское руководство стремилось наиболее полно использовать свое положение на путях между Россией и Европой, повышая транзитные тарифы. Негативно на оборот взаимной торговли влияли административные барьеры на пути торговли и инвестиций, импортозамещение по соображениям национальной безопасности и защиты национального производителя. Отметим, что в производстве товаров для белорусского рынка в РФ 
преобладают крупные компании, а в РБ для российского рынка малые и средние компании.

Не способствуют развитию взаимных торговых связей невысокие объемы взаимных прямых инвестиций. Накопленные в РБ прямые российские инвестиции за 2011-2016 гг. выросли незначительно с 8 до 8,5 млрд долл. Белорусские инвестиции в РФ в 2016 г. заметно выросли с 0,4 млрд до 2,05 млрд долл. [6, с. 24, 44], но в общем объеме инвестиций стран-партнеров это составляет незначительную величину. Рост взаимных инвестиций сдерживает как дефицит «длинных денег», так и большие риски инвестиционных проектов, связанные с различиями в рыночных институтах и общей неопределенности мировой конъюнктуры.

Сильное влияние на макроэкономику Беларуси оказывает состояние российской экономики, которое, в свою очередь, в большой мере зависит от цен на углеводороды. Резкое падение мировых цен на нефть вызвало резкое падение курса рубля, сокращение стоимостных объемов экспорта и импорта, рост инфляции и сокращение внутреннего спроса. В совокупности это вызвало падение белорусского импорта, что, учитывая его объемы, стало важным фактором ухудшения макроэкономических показателей в Беларуси в 20132016 гг.

Среди внутренних причин макроэкономической неустойчивости белорусской экономики А. Шурубович называет чрезмерную поддержку государством малоэффективных производств и несоразмерные с возможностями экономики социальные расходы [10, с. 116-117].

Беларусь и Россия сталкиваются с общими проблемами развития: при значительном научном потенциале и в целом довольно высоком уровне образования развитие экономики опирается в основном на заимствованные в третьих странах технологии. Имеющиеся научно-технические достижения не находят должного спроса у национальной экономики. В основном они доходят до стадии промышленных образцов и не выходят на уровень массового производства, поскольку на рынке уже имеются подобные товары от иностранных производителей по более низким ценам. Иными словами, жестким барьером развития государств выступает недостаточная конкурентоспособность национальных технологий и производимых на их основе новых изделий. С проблемой недостаточной конкурентоспособности экономик РБ и РФ связаны финансовые трудности, стагнация доходов населения, недостаточная инвестиционная активность.

В этих условиях страны стоят перед нелегким выбором будущего развития: либо бороться за долю на внутреннем и внешнем рынках в сегменте традиционных отраслей, получая от этого все меньшую прибыль, либо сконцентрировать усилия на инновационных производствах, порождаемых новой 


\section{РОССИЯ И МИР В ХХІ ВЕКЕ}

промышленной революцией, но выпуск которых связан с большими коммерческими рисками.

Решение этой дилеммы видится через повышение разными способами инновационной активности предприятий и организаций, что позволит либо снизить издержки в традиционных отраслях, либо выйти на рынок с новыми продуктами. Важной возможностью увязки внедрения новых технологий и на их основе массового выпуска инновационных товаров и услуг с формированием соответствующих рынков становится согласование национальных программ развития с выделением приоритетных производств в рамках евразийской интеграции. Это позволит выстроить единую стратегию их инновационного развития и реализовать трансграничную кооперацию в рамках приоритетных направлений, разделив между собой риски освоения новых высокотехнологичных производств.

Появление новых продуктов и их рынков связаны с практической реализацией евразийских технологических платформ (ЕТП). Совет ЕЭК утвердил 12 первых приоритетных ЕТП, которые объединяют более 400 ведущих научных и промышленных организаций Союза, готовых в 2018 г. реализовать более 130 совместных инновационных кооперационных проектов в наиболее перспективных отраслях [7, с. 145-150].

Совмещение модернизации традиционных производств, повышение их конкурентоспособности и одновременно создание новых производств в русле четвертой промышленной революции позволит широкая цифровизация экономики как на страновом уровне, так и в рамках ЕАЭС. С цифровой экономикой связаны надежды Беларуси и России на преодоление структурных проблем в экономике, ускорение темпов роста и устойчивый рост доходов населения. В целом евразийская интеграция делает первые шаги по созданию соответствующих институтов инновационного развития. Необходимость этих институтов очевидна. Причем лидерами инновационной модернизации на основе национальных разработок в рамках ЕАЭС по объективным условиям являются Беларусь и Россия. Это лидерство будет усилено в результате подписания в РБ декрета «О развитии цифровой экономики», который нацелен на создание в стране благоприятных условий для развития информационнокоммуникационных технологий. В этом контексте весьма актуально сфокусировать экономическое сотрудничество в рамках Союзного государства на поиск прорывных технологий и их внедрение в национальное производство.

\section{О пределах деградации взаимных}

\section{экономических связей РФ и Украины}

Сильное влияние неэкономических факторов на российско-украинские экономические связи в своей основе опирается на стремление Украины 
вырваться из «Русского мира», используя стратегический интерес Запада в сдерживании России. Пришедшие в результате «майдана» к власти антироссийски настроенные политические силы интерпретировали эти события как целенаправленную политику России, нежелающей сделать украинский народ богатым и счастливым. В этом контексте свертывание экономических связей стало важным элементом украинской политики «окончательного развода» с Россией. По мнению П. Порошенко, этот «развод» был оформлен безвизовым режимом между ЕС и Украиной, установленным в 2017 г. Тем не менее хотя доля РФ во внешней торговле за 2012-2017 гг. уменьшилась с 29 до 12\%, она по-прежнему занимает первое место среди торговых партнеров Украины.

Свертывание торговых связей по «национал-патриотическим» причинам бьет по доходам граждан, предприятий, бюджету, создает угрозу неисполнения кредитных обязательств перед МВФ и другими кредиторами страны, стало весомым фактором падения ВВП в 2013-2015 гг. Декларируемая нынешними властями страны миссия Украины как спасительницы Европы от «российской агрессии» отталкивает иностранные инвестиции, без которых трудно рассчитывать на устойчивый рост украинской экономики.

За 2012-2016 гг. объемы накопленных прямых российских инвестиций РФ в Украине уменьшились с 16,5 млрд долл. до 5,2 млрд долл., а украинских прямых инвестиций в РФ с 0,89 млрд долл. до 0,77 млрд долл. Сокращение связано с сокращением активов через их продажу или свертыванием деятельности в связи с большими коммерческими рисками и падением доходности. К фактическому обесценению активов компаний и банков с российским капиталом привели также падение курса гривны и периодические атаки на них украинских радикалов. Ситуацию отчасти спасает то, что российские владельцы этих активов имеют офшорную регистрацию [6, с. 19, 24].

С особой силой «революция достоинства» сказалась на поездках российских граждан в Украину, которые, по данным украинской статистики, за 2013-2017 гг. сократились почти в 7 раз (с 10,3 млн человек до 1,5 млн человек). Это поток складывался из поездок на курорты Украины, к родственникам, транзитных сообщений в Молдову, Болгарию и другие Балканские страны, туристических, служебных и прочих поездок. Встречный поток украинцев пострадал меньше, сокращение составило 1,6 раза (6,1 млн человек в 2013 г. и 4,4 млн человек в 2017 г.). Поездки граждан Украины в РФ в основном связаны с трудовой деятельностью.

В 2017 г. «национально-патриотическое» давление государства на украинский бизнес несколько ослабло. Об этом свидетельствует рост украинороссийской торговли на $29 \%$. Почти $2 / 3$ взаимной торговли - импорт из РФ. Его основу сегодня составляют каменный уголь, нефтепродукты, удобрения, некоторые виды машиностроительной продукции - те товары, которые не 
попали под взаимные санкции, но необходимы для ТЭК, металлургии и аграрного сектора Украины.

Представляется, что в ближайшие годы взаимные экономические связи будут неустойчивыми, но такого катастрофического сокращения, как в 20132016 гг., уже не произойдет. Важным ограничителем наращивания взаимной торговли в дальнейшем помимо взаимных санкций и импортозамещения становится продолжающаяся деиндустриализация Украины, в том числе и в связи с ее постепенным включением в экономическую систему ЕС. Для ЕС Украина представляет интерес как поставщик растительного и минерального сырья, а также полуфабрикатов, как источник дешевой рабочей силы и как инструмент давления на Россию. Со временем Украина будет обретать новые экономические функции в экономике Евросоюза, но в рамках ее периферийного статуса, например производить отдельные комплектующие для производства автомобилей и бытовой техники.

Центр тяжести в «политике развода» в 2017 г. был перенесен на сокращение возможностей непосредственной коммуникации граждан, поскольку идеи украинского национализма, замешанные на русофобии, не смогли сплотить народ и обеспечить внутреннюю стабильность.

Введение с конца декабря 2017 г. новых правил въезда в Украину на основе биометрических паспортов и с предварительным уведомлением, несомненно, ограничит возможности поездок не только граждан РФ, но и РБ в Украину. Украинской стороной параллельно проводятся меры по ограничению поездок украинских граждан в Россию как чисто пропагандистские, так и путем свертывания более дешевого регулярного пассажирского сообщения.

Для Украины первостепенно важно, чтобы ее геополитическое значение для Запада в плане сдерживания России не уменьшалось. За это западные спонсоры оказывают немалую финансовую помощь Украине, удерживают санкции в отношении России, т.е. выплачивают ей своего рода геополитическую ренту. Следует отметить, что после принятия Украиной в сентябре 2017 г. Закона об образовании, который ограничил право национальных меньшинств на обучение на родном языке, заметно обострились отношения с соседними странами ЕС. В связи с этим небезосновательно предположение, что проевропейская риторика украинских властей, по сути, стала прикрытием для создания моноэтничного украинского государства.

Обязательства Украины перед ЕС, США, НАТО по сдерживанию России вступают в определенное противоречие с требованиями международных финансовых организаций по урезанию социальных расходов, сокращению бюджетного дефицита и исправному исполнению долговых обязательств, что приводит к «сжатию» внутреннего потребления, которое сужает возможности экономического роста, прежде всего для украинской провинции, делает его зависимым от конъюнктуры на рынках основных экспортных товаров страны. 
Таким образом, возникает необходимость для Украины искать способы наращивания экспорта в Россию и другие страны СНГ не меняя политического курса. Все это сильно осложняет прогноз взаимных экономических отношений России и Украины на обозримую перспективу. Они будут определяться соотношением радикальных националистических и проевропейских сил, которое выявят выборы 2019 г. Скорее всего, доля РФ во внешней торговле Украины в ближайшие три-четыре года будет колебаться в пределах 10-12\% при сокращении социальных контактов, замораживании взаимных инвестиций и постоянных попытках нанести экономический и политический ущерб России.

\section{Отношения Беларуси и Украины: Преобладание прагматизма}

Сегодня при этнокультурной близости Беларусь и Украина - разные по идентичности страны. Снисходительно-пренебрежительное отношение проевропейской Украины к просоветской Беларуси после майдана заметно изменилось. В геополитическом плане для Украины весьма важно минимум обеспечить нейтралитет Беларуси в ее конфликте с Россией. Для Беларуси отношения с Украиной - важный элемент ее суверенитета и налаживания связей с ЕС.

Белорусско-украинские экономические отношения базируются на торговле, поскольку взаимные инвестиции имеют крайне незначительные объемы. Между странами действует режим свободной торговли. Украина и Беларусь в основном продают друг другу товары традиционного экспорта и имеют ограниченную производственную кооперацию. В 2017 г. во внешнеторговом обороте Украины доля их взаимной торговли составляла 4,6\%, а во внешнеторговом обороте Беларуси - 7,2\%.

Участвуя в Таможенном союзе (ЕАЭС и ЗСТ) в рамках СНГ, Беларусь смогла получить определенные торговые преимущества в результате разлада отношений между Россией и Украиной: она смогла нарастить продовольственный экспорт в РФ, заменив Украину, а в рамках ЗСТ СНГ увеличить экспорт жидкого топлива, производимого из российской нефти, на Украину, частично заменив прямые российские поставки на украинский рынок. Сейчас на Беларусь приходится около половины украинского импорта нефтепродуктов, которые составляют $2 / 3$ белорусского вывоза в Украину. В украинском экспорте в Беларусь преобладают сельскохозяйственное сырье и продовольственные товары. Беларусь в определенной мере компенсирует экономические потери России и Украины, возникшие от резкого сокращения их взаимных торговых связей. 
Перспективы наращивания взаимных инвестиций сегодня плохо просматриваются. Разрушение промышленного потенциала Украины расширяет возможности экспорта белорусской продукции. Но он будет сталкиваться с экспортом аналогичной продукции из ЕС, Турции и Китая. При этом вполне возможно усиление роли Беларуси как посредника в торговле между РФ и Украиной.

В целом значение Беларуси как международного партнера сильно выросло как для России, так и для Украины в результате их конфликта. К политическому и торговому значению следует добавить возрастание транзитного значения РБ для перевозок на направлении Китай - СНГ - Европа и на меридиональном направлении: страны Балтийского моря - страны Черного моря. Реализация «цифровых» амбиций РБ еще более повысит ее привлекательность для европейских и евразийских партнеров.

Сохранится ли «треугольник» в будущем? Или он превратится в «угол» с центром в Беларуси? Надеюсь, что сохранится. Но экономические взаимодействия в нем будут ослабевать по российско-украинской и белорусскоукраинской сторонам. Под влиянием ассоциации с ЕС продолжится трансформация экономики Украины в интересах европейских и американских компаний. Развитие экономики Беларуси и России будет происходить в рамках ЕАЭС, но с учетом национальных интересов. Важную роль в поддержании «треугольника» могут сыграть ТНК, но для этого нужно найти политическое решение проблемы Донбасса, а также наладить диалог между ЕС и ЕАЭС. В случае его успеха «треугольник» может обрести новую миссию связующего звена для европейской и евразийской интеграций.

\section{Библиография}

1. Дзермант А. Беларусь: Особенности государственной идеологии и национальной идентичности // Центр Льва Гумилёва. 2015. 18 июня. URL: http://www.gumilevcenter.ru/belarus-osobennosti-gosudarstvennojj-ideologii-i-nacionalnojj-identichnosti/ (Дата обращения 30.03.2018.)

2. Головаха Е.И., Панина Н.В. Основные этапы и тенденции трансформации украинского общества: От перестройки до парламентского кризиса 2007 г. // Российская модернизация: Размышления о самобытности. М.: Три квадрата. 2008. С. 312-316.

3. Кочетков В.В. Идентичность в международных отношениях: Теоретические основы и роль в мировой политике // Вестник МГУ. 2010. Сер. 25: Международные отношения и мировая политика. № 1. С. 20-24.

4. Крылов М., Гриценко А. Идентичности на Украине: Вызовы современности - эхо прошлого? // Мир перемен. М., 2015. № 2.

5. Кузнецов А.В. Судьба англосаксонского глобализма // Мир перемен. 2015. № 3. C. $146-148$.

6. Мониторинг взаимных инвестиций в странах СНГ. 2017. СПб.: Центр интеграционных исследований, 2017. 62 с. 
7. Сидорский С.С. Инновации как фактор устойчивого развития реального сектора государств - членов ЕАЭС // Стратегия развития экономики Беларуси: Вызовы, инструменты реализации и перспективы: Сб. научных статей. Минск: Институт системных исследований в АПК НАН Беларуси, 2017. Ч. 1. С. 145-150.

8. Толочко П. «Русский мир» и Украина // Еженедельник «2000». 2012. 14 июня. № 23. C. 4. URL: http://www.2000.ua/v-nomere/forum/puls/russkij-mir-i-ukraina_arhiv_art.htm (Дата обращения: 30.03 .2018 .)

9. Тренин Д.В. Интеграция и идентичность. Россия как «новый Запад». М.: Европа, 2006. 402 c.

10. Шурубович А.В. Белорусская экономическая модель перед лицом тяжелых испытаний // Россия и современный мир. 2017. № 3. С. 116-132.

\section{References}

Dzermant A. Belarus': Osobennosti gosudarstvennoj ideologii i nacional'noj identichnosti // Centr L'va Gumileva. 2015. 18 June. URL: http://www.gumilev-center.ru/belarus-osobennostigosudarstvennojj-ideologii-i-nacionalnojj-identichnosti/ (Data obrashhenija: 30.03.2018.)

Golovaha E.I., Panina N.V. Osnovnye jetapy i tendencii transformacii ukrainskogo obshhestva: Ot perestrojki do parlamentskogo krizisa $2007 \mathrm{~g}$. // Rossijskaja modernizacija: razmyshlenija o samobytnosti / Red. Pain Je.A., Volkogonova O.D. M.: Tri kvadrata. 2008. P. 312-316.

Kochetkov V.V. Identichnost' v mezhdunarodnyh otnoshenijah: Teoreticheskie osnovy i rol' v mirovoj politike // Vestnik MGU. Mezhdunarodnye otnoshenija i mirovaja politika. 2010. Ser. 25. N 1. P. 20-24.

Krylov M., Gritsenko A. Identichnosti na Ukraine: Vyzovy sovremennosti - ekho proshlogo? // Mir peremen. Moscow, 2015. N 2.

Kuznecov A.V. Sud'ba anglosaksonskogo globalizma // Mir peremen. 2015. N 3. P. 146-148.

Monitoring vzaimnyh investicij v stranah SNG. 2017. Saint-Petersburg: Centr integracionnyh issledovanij, 2017. $62 \mathrm{p}$.

Shurubovich A.V. Belorusskaja jekonomicheskaja model' pered licom tjazhelyh ispytanij // Rossija i sovremennyj mir. 2017. N 3. P. 116-132.

Sidorskij S.S. Innovacii kak faktor ustojchivogo razvitija real'nogo sektora gosudarstv - chlenov EAJeS // Strategija razvitija jekonomiki Belarusi: Vyzovy, instrumenty realizacii i perspektivy: Sb. nauchnyh statej. Minsk: Institut sistemnyh issledovanij v APK NAN Belarusi, 2017. Vol. 1. P. $145-150$

Tolochko P. «Russkij mir» i Ukraina // Ezhenedel'nik «2000». 2012. 8-14 June. N 23. P. 4. URL: http://www.2000.ua/v-nomere/forum/puls/russkij-mir-i-ukraina_arhiv_art.htm (Data obrashhenija: 30.03 .2018 .)

Trenin D.V. Integracija i identichnost'. Rossija kak «novyj Zapad». M.: Evropa. 2006. 402 p. 